\title{
Making Math Accessible to All Students: Effective Pedagogy?
}

\author{
Bina Kachwalla \\ CORE Education
}

Making mathematics accessible to all students depends heavily on teacher beliefs. The belief that all children can do mathematics if they are seen as mathematicians. We do not teach mathematics, we teach mathematicians. The mathematics pedagogical practice I refer to in this article pertains to developing communities of learners who, like mathematicians, work collaboratively to solve problems. The teacher's role is to orchestrate classroom discussions by creating a conducive climate in which students start thinking, discussing, proving, sharing their ideas to solve problems. In this article I will: explore teacher beliefs on education; outline norms to create a conducive classroom climate for learning; explore the notion of orchestrating classroom discussions, and encourage teachers to design challenging low-floor highceiling tasks that allow all students to access. Teacher beliefs resulting in making a pedagogical shift is needed to make math accessible to all.

Keywords: effective pedagogy, collaboration, classroom discourse, low-floor high-ceiling tasks

\section{INTRODUCTION}

All children, when given appropriate support, can learn mathematics for understanding. It is important that teachers of young children teach mathematics in a way that promotes understanding, that helps children to make key connections, and that recognizes opportunities to develop key processes through which students are able to articulate their thinking with reasoning. One hallmark of mathematical understanding is a student's ability to justify why a given mathematical claim or answer is true, or why a mathematical rule makes sense. Students may be very efficient in knowing their basic facts. However, if they do not display flexibility in applying these facts in real life situations, they do not have mathematical understanding. To explore this notion of understanding further, we need to delve into the practice of effective teaching. Effective teaching occurs in mathematics classrooms where students are allowed to solve problems or to approach tasks in ways that make sense to them. Students in these classrooms inquire into challenging mathematical tasks that provide access to all students. The environment is innovative and conducive to learning and students work collaboratively in flexible, social and/or mixed ability groupings. In order to make this pedagogical shift to effective teaching practice teachers need to investigate their own beliefs on education and provide the classroom climate that enables student discourse.

\section{INVESTIGATE TEACHER BELIEFS}

When you believe in your students, they do better (Boaler, 2015). As a mathematics facilitator running professional development courses over the past twelve years, I have come across numerous teachers in 
many schools who are oblivious to, or confused about their own beliefs in mathematics teaching and learning. When asked many years ago, I was unaware of my own beliefs. Since then I have investigated my beliefs thoroughly and have changed them as well. Boaler's (2015) research into teacher beliefs has shown the following ideas teachers have been guided to revisit their beliefs through research.

\section{Everyone Can Learn Math to the Highest Levels}

For many years, the idea about who could be a 'math person' was based on the conjecture that some people are math people and others are not (Boaler, 2015). However, this conjecture has been disproved by brain science which shows that the brain grows and changes so that no one is born with or without a maths brain (Boaler, 2015). Mathematical pathways form in the brain through learning. In a range of studies pioneered by Carol Dweck (2012), it has been shown that people who have a growth mindset believe that they can learn anything. These people tend to achieve at higher levels, in school and in life. A growth mindset is the understanding that abilities and intelligence can be developed. Students who have a fixed mindset believe that they are not math people, and lack confidence in learning mathematics. Our role as teachers is to believe in our students and encourage them to believe in themselves as mathematicians.

\section{Mistakes and Challenges Lead to New Learning}

Many teachers as well as parents are not comfortable when students make mistakes in mathematics. As a result students are made to believe that mathematics requires correct answers and that mistakes are not acceptable. We now know that mistakes are stepping stones to our learning (Boaler, 2015). While learning to ride a bicycle, we encourage children when they fall and help them to try again. However, many teachers cannot allow students to fail or make mistakes in mathematics and routinely try to rescue them. The messages teachers and parents need to give to students and themselves are that mistakes are valued because they enable new learning to occur. Our pathways to learn improves, as synapses in the brain ignite when students make mistakes which in turn cause the brain to grow (Dweck, 2012).

\section{Questions \& Discussions Deepen Your Mathematical Understanding}

One of the highlights in mathematics teaching is shifting from single desk classroom arrangements to working in groups. Teachers' beliefs in how students learn have changed significantly. Students are given opportunities to have discussions, develop convincing arguments, and to ask questions of each other while they solve challenging problems. The tasks are more open-ended where there are multiple pathways to find solutions. This provides possibilities for many students to get an entry point to work towards the solution (Smith \& Stein, 2018). This research shows us that when students are skilled in asking questions the process is linked to high achievement. Brain science also tells us that when we answer a question, and retrieve information from our brain, that information is embedded in the brain, being accessible for further learning.

\section{Depth Is More Important Than Speed!}

Many people incorrectly believe that being good at maths means being fast at maths. We do not need students to compute quickly, we need them to think deeply, connect ideas, to reason and justify. As well as the ability to discuss and question ideas, students need to develop metacognition skills to deepen their thinking which requires time. Teachers and parents who believe that speed makes students efficient in math learning need to be informed about fluency in mathematics. Fluency requires all three components: accuracy, efficiency and flexibility. Students who lack fluency might know their basic facts well, but are unable to apply these facts to solve real life math problems. Messages students need to receive is that teachers do not value fast work, instead they value creative representations of ideas. Mathematical thinking is all about deep thinking and not the speed. Teachers can encourage this by driving mathematical discussions in their classroom by valuing students who are deep thinkers and allowing them to share their ideas. 


\section{OUTLINE CLASSROOM NORMS TO DEVELOP CONDUCIVE LEARNING CLIMATE}

The positive changes to teacher beliefs outlined in the previous section will support a classroom culture that will nurture and value all students thinking. Teachers who have introduced classroom norms based on the beliefs that students learn collaboratively have had success in increasing student confidence to communicate their ideas mathematically. Two major goals, according to Chapin et al., (2009), in setting up classroom norms are respectful discourse and equitable participation. These goals are important for students to feel safe and valued members of the community of learners. Teachers should be mindful of the practice that no one is ignored or intimidated in the classroom. With these goals in mind suggested norms could be as follows: No one in the classrooms is ridiculed or insulted for taking risks in sharing their ideas. Participation is equitable whereby each person has a fair chance to ask questions and share their ideas even if that idea is incorrect. Celebrating mistakes makes the classroom vibrant and encourages rich discussions.

The classroom climate that has classroom norms well established allows students to take risks, to share their thinking, value others opinions, and have convincing mathematical arguments with other students. They are also able to justify their ideas using representations and proving their ideas in various ways. Making math accessible to all students, becomes a reality in such a classroom climate. One of the students, when asked what was his learning after a math lesson, replied: "I learnt that I can make mistakes but I can fix them too". Making a mistake in learning is a way of life in these classrooms. Students feel confident to attend to challenging tasks because they have developed a growth-mindset and are not shy of making mistakes. Ideally, these behaviours in learning are valued across the curriculum and not only in mathematics classrooms.

\section{ORCHESTRATING CLASSROOM DISCOURSE}

A collaborative classroom climate will enable teachers to orchestrate effective classroom discourse. Mathematics is about students making conceptual connections and clearly communicating their thinking. For more than two decades, the National Council of Teachers of Mathematics has been urging teachers to emphasize students' discourse as part of mathematics teaching and learning (Smith \& Stein, 2018). The mathematical thinking of many students is supported by listening to what their peers are thinking while at the same time learning to see things from other perspectives. Students are able to clarify and strengthen their thinking and develop a mathematical language when expressing and justifying their solution methods. Teachers can spot student misunderstandings much more easily when they are revealed by a discussion.

Chapin et al., (2009), have introduced academically productive talk moves as a tool for teachers to use in the classrooms to orchestrate classroom discourse. These talk moves are useful to increase quality talk in the classroom. Students need to develop skills to implement meaningful discussions about the challenging tasks they are solving collaboratively. If students participate in the group discussion, they should be able to share their thinking and reasoning so that their thinking is understood by others. This opportunity to verbalise allows students to clarify their own thinking. Secondly, students should be able to actively listen to others explanations. If students cannot listen to each other, they won't be able to engage in productive talk moves. Thirdly, students should be able to justify and show the reason behind their argument on solving a problem which apparently leads to students developing metacognition skills and deepening their own reasoning. Finally, productive talk moves help students absorb the ideas and reasoning of other students and logically respond to them. If students are not reasoning, then they are not really doing mathematics (Boaler et al., 2017, p7). This is when in depth discussion can take place, the discussion that will support robust learning. Students are obliged to prove their reasoning. The act of proving is about connecting and communicating ideas. Students need to be able to convince themselves of their idea, convince a friend and be able to convince a skeptic. Convincing a skeptic pushes the student's to a deeper level of reasoning.

To support teachers to facilitate student discourse in their mathematical classrooms Smith \& Stein (2009) have proposed the Five Practices Model. These five practices involve, anticipating, monitoring, selecting, sequencing and connecting. The more math teachers know, the easier it is for them to find value 
in the ways their students think. It is suggested by these researchers that it is important to anticipate all the likely responses students might offer to solve a given problem. A teacher's mathematical knowledge enables her to connect one student's interesting idea to another's. The five practices for orchestrating productive mathematical discussions offer the actions that can develop and sustain the belief that both math and students matter (Smith et al., 2019).

The Five Practices Model has presented an approach which allows teachers to transition into practicing classroom discourse using rich mathematical tasks. Some of the teachers applying the five practices say, "They [the students] have opportunities to talk about a problem, talk about the way they solve it, and bounce ideas off each other" (Smith et al., 2019, pp.1). Melanie Cifonelli, director of mathematics, observes, "I've seen a mindset shift in many of our students when I walk into classrooms that use the five practices on a regular basis." (Smith et al., 2019, pp.7).

\section{LOW-FLOOR HIGH-CEILING TASKS}

In order to incorporate the Five Practices Model into classroom teaching, we need a mathematics curriculum which is designed around problem solving. In this model students are given low-floor highceiling tasks, showing them that everyone can engage and access mathematics problems and solve them at their own pace. Teachers using the Five Practices Model believe that the mathematics class is about learning and not performing. Meaningful learning of mathematics leads towards understanding mathematical concepts and making connections. As students develop deep mathematical thinking, teachers need to encourage them to extend and generalize their ideas through reasoning, justifying and proving.

Low-Floor High-Ceiling Tasks (LFHC) are tasks where all students can access the problems but they can be extended to high levels. These tasks allow students to work at different paces and the teacher's facilitation enables the students to deepen their conceptual thinking. The main reason students like LFHC tasks is because they provide opportunities for all children to work like mathematicians. These tasks also promote a positive classroom culture because the whole class is working on the same activity. This allows the students to expose themselves to higher conceptual thinking expressed by their peers. This collaborative learning provides equity in our classrooms.

In more traditional mathematics classroom settings it has been noted that some students lose their confidence in solving problems because the tasks require one answer and if these students are not quick to give the correct response to the task, they give up quite easily. Let us look at an example which could be used in a traditional classroom [ Fig 1].

\section{FIGURE 1}

The length and the width of the rectangle is $6 \mathrm{~m}$ and $12 \mathrm{~m}$. Find the area of the rectangle.

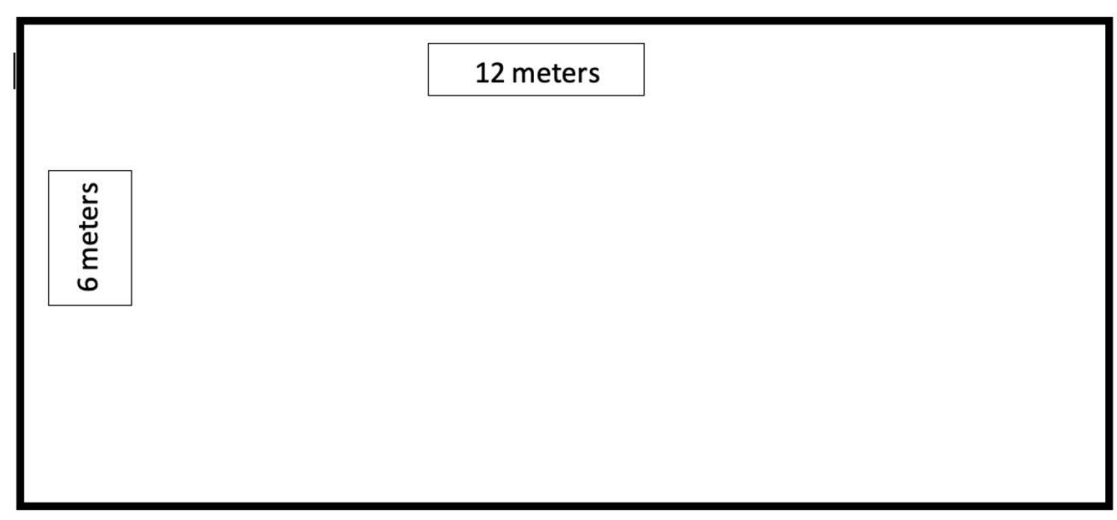


What type of question is this? Does this question allow students to think in a variety of ways? Traditional mathematical teaching is asking for one correct answer e.g 12 X $6=72$ squared meters Students who are not good at either knowing the rule or making the appropriate calculations develop anxiety towards mathematics. The emphasis in these classrooms is towards accurate mathematical calculations rather than mathematical fluency and creativity.

However, if the problem is designed to be more creative and open-ended, then many students will be able to participate and be motivated to solve it. An example of a low-floor high-ceiling question is shown below. The previous traditional math example in this article is modified into a low floor high ceiling task:

Task: You have 36 meters of fence to make a run for your pet rabbit. How many rectangular [4 sided] enclosures can you possibly create for your pet using all 36 meters of fencing material?

This is an open-ended problem. Children can access the problem at different entry points. It also provides a wide range of possible solutions as shown in the fig 2 to make a rectangular enclosure. Student participation and engagement leads to rich classroom discourse and students use productive talk moves to share ideas, justify their thinking and have challenging mathematical arguments to learn from each other. Visual representation helps students greatly.

\section{FIGURE 2}
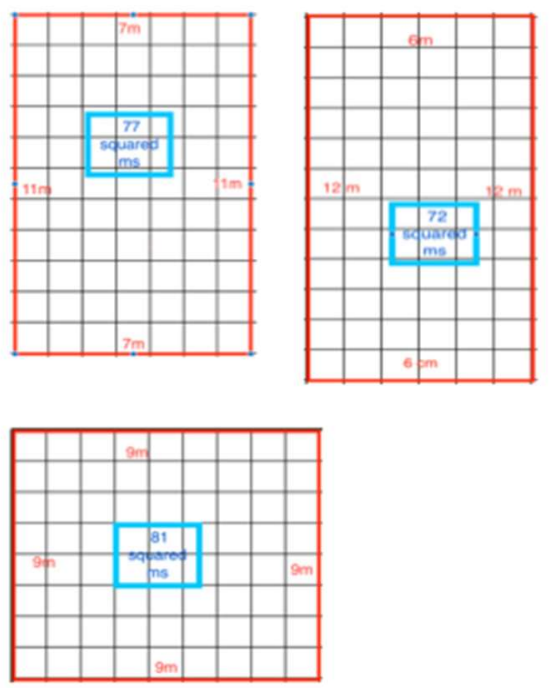

\section{Students get exposed to different dimensions.}

Perimeter of these rectangles is the same [36m], the area changes as the size of the shape changes

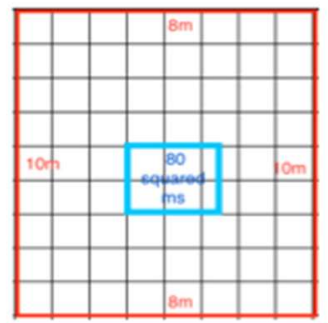

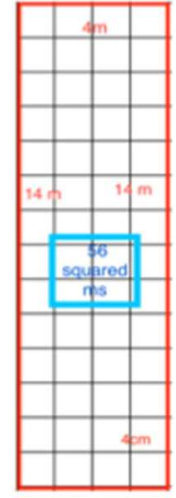

In a situation where teachers are using the Five Practice Model in their classroom, they allow students to learn from each other. Some of the students who are visual learners, use the grid paper representation to explain their thinking. They are also able to count the squares to find the area of the rectangles assisted by their drawings of the grids. Some students may use the basic area and perimeter relationships and try to justify their thinking. We want every learner in our classroom to be both the user of mathematical equations and the illustrator of their mathematical understanding. These tasks guide students to deepen understanding, promote productive struggle, and increase flexibility by using and connecting mathematical representations. Some teachers have experienced that when they offer a low-floor high-ceiling task to all students they open the door for students to go further than they might have expected. When I have offered this challenging task in most schools I have worked in I have received an overwhelming variety of responses from students. Most students have been able to make connections about the relationship between the perimeter and the area. When asked to frame a statement on their learning, their responses have been... 
- "The perimeter of all these rectangles have been the same, the area changes according to the shape of the rectangles".

- "If the shape is a square it gives maximum area".

- "I wonder if this relationship would be the same if we have the area remaining the same, would the perimeter change?".

- When the shape gets closer to the square shape, the area gets larger".

- "Most efficient way of finding the area of a rectangle is to multiply the length and the width of the shape".

These responses show depth of understanding about area and perimeter. Students also get exposed to different dimensions. The task becomes a rich task because the students discuss the possible solutions and the relationships between the area and perimeter, which is the goal of the lesson. Teachers who participate in this new learning can experience that this math problem is accessible to all students. All students have been engaged and all participated. Some students who are finding the area by counting the squares of the shape learn to link that with the length and the width of the shape leading to the multiplicative thinking. Teachers need to follow up with similar examples of this task to enable the students to consolidate this multiplicative abstract thinking. Extension to this task could provide opportunity for students to investigate relationships when the area remains the same, but the perimeter of the shape varies. Most teachers experience an 'aha' moment when students surprise them with responses they did not expect. It is important for teachers when providing these low-floor high-ceiling tasks not to make assumptions about their students capabilities when solving these problems.

\section{CONCLUSION}

With changed teacher beliefs about teaching and learning through practicing the Five Practices Model, students have shown significant confidence in learning mathematics. They have started believing in their ability to learn maths. Students are motivated to learn and are engaged in solving challenging tasks. It actually becomes a reality that mathematics is accessible to all and that students are able to achieve at a higher level. Teachers provide opportunities of collaborative learning through flexible grouping, conducive learning classroom climate and establishing norms that encourage student discourse while solving problems.

The following links provide examples of low-floor high-ceiling tasks that readers might like to try in their classrooms.

- http://youcubed.stanford.edu/tasks/ (under grades choose Low Floor High Ceiling)

- nrich.maths.org/7701/index

- http://www.insidemathematics.org/problems-of-the-month

- https://www.illustrativemathematics.org

I would like to conclude by emphasising the urgency of collaborative practice that enables all students to access challenging mathematical tasks. We need rich mathematical classrooms, which incorporate communities of inquiry, collaboration, and promote communication and imagination. In essence, rich tasks encourage children to think creatively, work logically, communicate ideas, synthesise their results, analyse different viewpoints, look for commonalities, and evaluate findings. 


\section{REFERENCES}

Boaler, J. (2015). Mathematical Mindsets: Unleashing Students' Potential through Creative Math, Inspiring Messages and Innovative Teaching. New York, John Wiley \& Sons Inc.

Boaler, J., Munson, J., \& Williams, C. (2017). Mindset Mathematics: Visualizing and Investigating Big Ideas, Grade 4. San Francisco, John Wiley \& Sons, Inc.

Chapin, S.H., O’Connor, C., \& Anderson, N.C. (2009). Classroom Discussions in Math A Teacher's Guide for Using Talk Moves to Support the Common Core and More, Grades K-6. Sausalito, Math Solutions.

Dweck, C. (2012). Mindset: Changing the way you think to fulfill your potential. Great Britain, Constable and Robinson Ltd.

Smith, M., Bill, V., \& Williams, C. (2019). The Five Practices in Practice [Elementary]: Successfully Orchestrating Mathematics Discussions in Your Elementary Classroom. California, NCTM CORWIN.

Smith, M.S., \& Stein, M.K. (2018). Five Practices for Orchestrating Productive Mathematical Discussion. Reston VA, NCTM CROWN. 